\title{
Terapia Comunitária Integrativa como estratégia de promoção da saúde nas universidades
} Integrative Community Therapy as a health promotion strategy in universities Terapia Integrativa Comunitaria como estrategia de promoción de la salud en las universidades

Roberto Nascimento de Albuquerque (D)

Centro Universitário de Brasília (UniCEUB), Brasília, Distrito Federal, Brasil

\section{RESUMO}

Objetivo: Verificar a atuação da Terapia Comunitária Integrativa como estratégia de promoção da saúde no âmbito universitário. Método: Trata-se de uma revisão integrativa de literatura, realizada em dezembro de 2020. Teve como critérios de inclusão artigos em inglês, espanhol ou português, publicados nos últimos dez anos, disponíveis na íntegra, que contemplassem o tema proposto para esta pesquisa e estivessem publicados nas bases de dados da Biblioteca Virtual em Saúde (BVS), do Portal de Periódicos CAPES e da Scientific Literature (SCILIT). Resultados: Foram encontrados 398 artigos, dos quais 18 foram selecionados para este estudo. Instituições de ensino superior brasileiras e estrangeiras implantaram e implementaram as rodas de Terapia Comunitária como espaços de acolhimento, escuta ativa, criação de vínculos, bem como de promoção da saúde e promoção da saúde mental de seus estudantes universitários. Conclusão: Constatou-se que a Terapia Comunitária Integrativa é uma potente ferramenta de promoção da saúde e, nos últimos cinco anos, essa prática tem se fortalecido nas universidades.

Palavras-chave: Terapias Complementares; Saúde Mental; Universidade; Promoção da Saúde.

\footnotetext{
Histórico do Artigo

Recebido

03 Março 2021

Aprovado

03 Maio 2021

\section{Correspondência}

Roberto Nascimento de Albuquerque 707/907 - Campus Universitário SEPN Asa Norte, CEP: 70790-075 - Brasília-DF. E-mail: roberto.albuquerque@ceub.edu.br

Como citar

Albuquerque RN. Terapia Comunitária Integrativa como estratégia de promoção da saúde nas universidades. Rev. Saúde Col. UEFS 2021; 11(1): e6611.
} 


\section{INTRODUÇÃO}

A entrada na universidade é um importante marco no início da vida adulta de muitos jovens. Esse ambiente é novo e cheio de expectativas, mas também repleto de normas, metodologias, grupos e pessoas desconhecidas. Isso faz com que os jovens desenvolvam habilidades que possam corresponder à todas essas cobranças ${ }^{1,2}$.

A vida universitária tem revelado que, desde o início, os jovens precisam desenvolver complexas estruturas emocionais e habilidades cognitivas para enfrentar a vivência acadêmica permeada de circunstâncias estressoras e causadoras de ansiedade e desgaste emocional, tais como avaliações, apresentações de seminários, estágios curriculares supervisionados, dentre outros ${ }^{3,4}$.

Atreladas às exigências acadêmicas, cobranças familiares e pessoais também acometem esses estudantes como a não aceitação da família em relação à escolha do curso superior, do estudante tentar conciliar o trabalho, a faculdade e atividades do lar, bem como as diferentes expectivativas em relação ao futuro profissional e mercado de trabalho ${ }^{5}$.

Nesse contexto, o sofrimento psíquico desse estudante durante a graduação pode resultar em baixo rendimento acadêmico e de aprendizagem, implicar no aumento da insegurança e da baixa autoestima. Assim, mesmo que o universitário possua um bom nível de conhecimento teóricoprático, as questões emocionais envolvidas no processo formativo podem ser desencadeadoras de transtornos mentais e possível abandono do curso superior ${ }^{6}$.

Portanto, faz-se necessário que as universidades criem espaços de escuta e acolhimento que possam identificar os potenciais estressores causadores de sofrimento psíquico entre estudantes para promover saúde mental, prevenir transtornos físicos e mentais, além de tentar recuperar aqueles que já se encontram adoecidos mentalmente ${ }^{7}$.

Frente ao exposto, o ambiente universitário pode se tornar um lugar propício à realização de práticas integrativas e complementares em saúde, e, em especial, a Terapia Comunitária Integrativa (TCI), no intuído de suavizar ou reduzir o sofrimento vivenciado no período acadêmico.

As rodas de TCI, como são conhecidas, têm a capacidade de articular diferentes dimensões do indivíduo - a biológica, a social e a política. A roda tem como ponto de partida uma situação-problema apresentada por algum indivíduo que participa da roda. A partir dessa situação, os indivíduos da roda terão a oportunidade partilhar sentimentos e experiências vivenciadas e parecidas; isso estimula e favorece o crescimento de todos os participantes para adquirirem maior autonomia, consciência e corresponsabilidade ${ }^{8}$.

A TCI foi criada, em 1987, pelo médico psiquiatra Adalberto de Paula Barreto, em Fortaleza, Ceará. Seu objetivo era estabelecer um recurso no processo saúde-doença de pessoas que estavam em situação de sofrimento psíquico intenso ${ }^{9}$.
A partir de 27 de março de 2017, o Ministério da Saúde incluiu a Terapia Comunitária Integrativa no rol de atividades da Política Nacional de Práticas Integrativas e Complementares do Sistema Único de Saúde. O Ministério da Saúde define a TCI como

uma prática de intervenção nos grupos sociais e objetiva a criação e o fortalecimento de redes sociais solidárias. Aproveita os recursos da própria comunidade e baseia-se no princípio de que se a comunidade e os indivíduos possuem problemas, mas também desenvolvem recursos, competências e estratégias para criar soluções para as dificuldades. É um espaço de acolhimento do sofrimento psíquico, que favorece a troca de experiências entre as pessoas ${ }^{10}$.

A TCI está fundamentada em cinco eixos teóricos: o Pensamento Sistêmico, a Teoria de Comunicação, a Antropologia Cultural, a Pedagogia de Paulo Freire e a Resiliência ${ }^{10,11}$. Acredita-se que as crises e os problemas podem ser entendidos e resolvidos, caso sejam percebidos como partes integradas de uma rede complexa, onde tudo está ligado, cada parte dependente da outra (Pensamento Sistêmico). E, para tentar solucionar esses problemas, a comunicação entre as pessoas é um elemento-chave que une os indivíduos, a família e a sociedade (Teoria de Comunicação). Atrelados a isso, a cultura tem um papel fundamental na maneira de se pensar o mundo e assumir a própria identidade como pessoa e cidadã (Antropologia Cultural) . $^{8}$

A Terapia Comunitária também se ancora nos pressupostos de Paulo Freire, o qual afirma que ensinar é o exercício do diálogo, da troca, da reciprocidade, ou seja, de um tempo para falar e de um tempo para escutar, um tempo para aprender e um tempo para ensinar ${ }^{12}$. Por fim, a resiliência, um dos eixos teórico-filosóficos da TCI, refere que o sofrimento e a vitória de cada um, expostos ao grupo, são utilizados como matériaprima de consciência social ${ }^{13}$.

A metodologia das rodas de TCI possui seis etapas: acolhimento, escolha da inquietação, contextualização, problematização, rituais de agregação e conotação positiva, e avaliação. No acolhimento, são dadas as boas-vindas, apresentase os objetivos da roda, suas regras (fazer silêncio, falar somente da própria experiência, não dar conselhos, sugerir músicas e respeitar a história de cada pessoa) e finaliza com uma dinâmica de aquecimento. Em seguida, na escolha da inquietação, os participantes são incentivados a apresentarem suas aflições e sofrimentos. Após a manifestação dos temas realiza-se uma votação entre os temas propostos, o qual será eleito como o tema da roda daquele dia ${ }^{14}$.

Com a escolha do tema, o terapeuta solicita mais informações sobre $\mathrm{o}$ assunto à pessoa que trouxe $\mathrm{a}$ inquietação para a roda, para que se possa compreender o contexto que se encontra o problema (fase de contextualização); ressaltase que, nesse momento, todos da roda podem perguntar ao participante que teve o tema escolhido. Em seguida, na problematização, o terapeuta atribui o mote - pergunta- 
chave que permite a reflexão geral do grupo: quem viveu/ vive uma situação parecida e o que fez/está fazendo para resolvê-la? Nesse momento, todos os participantes da roda são incentivados a partilhar suas experiências ${ }^{15}$.

Por fim, o terapeuta realiza rituais de agregação e conotação positiva o qual ressalta o que observou de positivo nas histórias contadas no grupo, além reconhecer, valorizar e agradecer o esforço, a coragem, a determinação e a sensibilidade de todos de tentarem superar as dificuldades. Por fim, o terapeuta solicita aos componentes da roda que possam relatar o que aprenderam ou o que levarão de aprendizado nas experiências de vida contadas ${ }^{8}$.

Apesar da consolidação da TCI como umas das práticas integrativas e complementares em saúde no Brasil, por meio de pesquisas e relatos de experiências em diversos setores da sociedade, como na atenção primária, em hospitais, em centros de atenção psicossociais, comunidades religiosas, centros comunitários, ressalta-se que poucos estudos foram desenvolvidos no sentido de retratar a implantação dessas rodas de terapia no âmbito universitário.

Portanto, o objetivo dessa pesquisa é verificar a contribuição das rodas de Terapia Comunitária Integrativa como estratégia de promoção da saúde mental, no âmbito universitário.

\section{MÉTODO}

Trata-se de uma revisão integrativa de literatura, a qual tem sido descrita como um método de pesquisa que sintetiza múltiplas pesquisas publicadas e inclui o aprofundamento de estudos relevantes que sustentem a tomada de decisão e a melhoria das ações pertinentes à determinados assuntos ${ }^{16}$.

A pesquisa foi realizada a partir da seguinte questão norteadora: de que modo a TCI tem contribuído para promoção da saúde mental dos estudantes universitários? Por conseguinte, buscou-se na literatura vigente evidências da implantação da TCI em universidades brasileiras e estrangeiras; e verificar a hipótese de que essa terapia traz claros benefícios aos estudantes universitários dessas instituições.

Para tanto, realizaram-se buscas por artigos publicados nas seguintes bases de dados: Biblioteca Virtual em Saúde (BVS), Portal de Periódicos CAPES e Scientific Literature (SCILIT). A coleta de dados ocorreu no mês de dezembro de 2020 e contou com os seguintes critérios de inclusão: artigos em inglês, espanhol ou inglês, publicados, entre 2010 e 2020, disponíveis na íntegra, e que contemplassem o tema proposto para esta pesquisa. Como critérios de exclusão: teses, dissertações, capítulos de livros, manuais, artigos de revisão de literatura, ensaios teóricos/artigo de reflexão e artigos que abordassem a Terapia Comunitária Integrativa, mas em outros ambientes que não fossem dentro de universidades.

Como não existe o descritor "Terapia Comunitária" no rol de Descritores em Ciências da Saúde (DeCS), observouse que os artigos publicados e que contemplavam a terapia comunitária integrativa utilizaram-se de diferentes descritores para referirem-se a tal prática. Desta maneira, foi efetuada uma busca avançada com o operador booliano "OR" e "AND" com as palavras-chave "terapias complementares" OR "terapia comunitária" AND "universidades" e que constassem esses termos no título ou resumo.

\section{RESULTADOS E DISCUSSÃO}

Inicialmente foram encontrados 378 artigos, sendo 122 artigos, na BVS, 126 artigos no Periódicos CAPES e 130 artigos na SCILIT.

Foi realizada uma leitura criteriosa dos artigos selecionados, inicialmente, pelos títulos e resumos; destes, 355 artigos foram excluídos, pois não se adequavam aos critérios de inclusão e exclusão. Os 23 artigos restantes foram lidos na íntegra e 5 foram excluídos por não contemplarem diretamente os objetivos da pesquisa. Desta maneira, 18 artigos foram selecionados, 3 da BVS, 9 do Periódicos CAPES e 6 da SCILIT, conforme Figura 1.

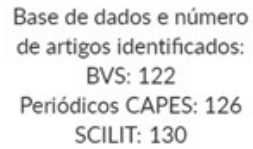

Base de dados e número

de artigos identificados: BVS: 122

Periódicos CAPES: 126 SCILIT: 130
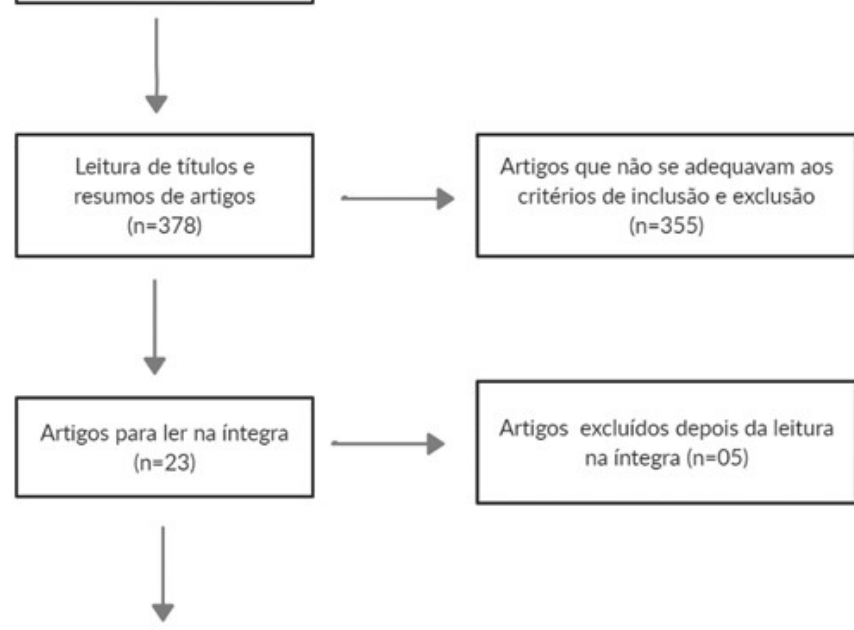

Artigos selecionados para

o escopo desta pesquisa $(n=18)$

Figura 1. Fluxograma de seleção dos artigos para a revisão integrativa Fonte: Elaborado pelo autor a partir da revisão de literatura.

Observou-se que 14 dos 18 artigos selecionados foram divulgados nos últimos 5 anos (2016-2020), representando $77,8 \%$ das publicações. Ressalta-se que houve um aumento exponencial de publicações sobre a TCI nas universidades, no ano de 2020, conforme Figura 2.

Em relação ao tipo de estudo, 10 deles $(55,6 \%)$ foram relatos de experiência, 7 pesquisas qualitativas $(38,9 \%)$ e 1 $(5,5 \%)$ do tipo quase-experimental. 


\begin{tabular}{|c|c|c|c|c|c|c|c|c|c|c|c|c|c|c|c|c|c|c|}
\hline 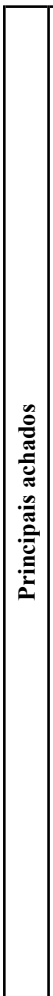 & 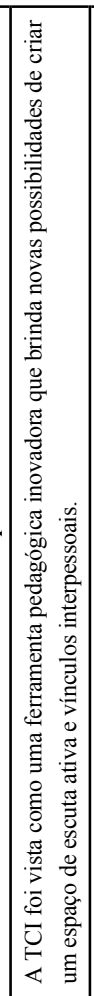 & 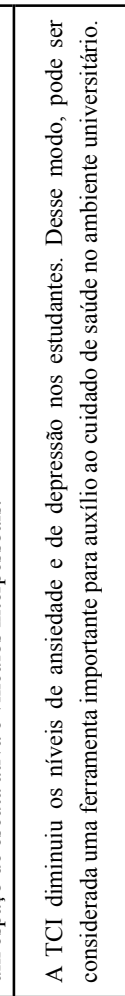 & 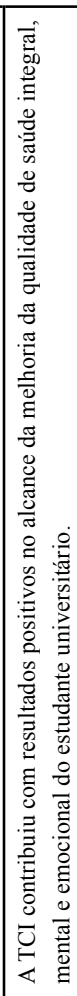 & 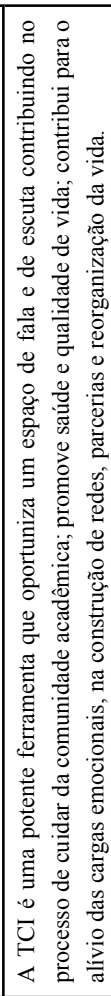 & 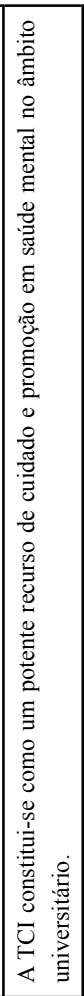 & 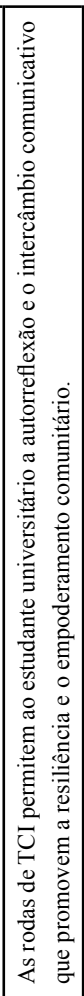 & 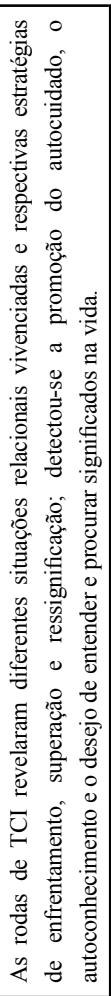 & 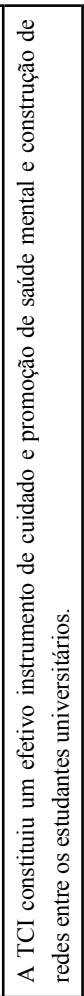 & 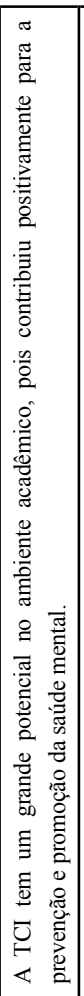 & 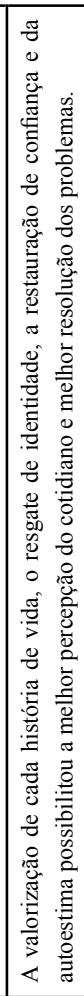 & 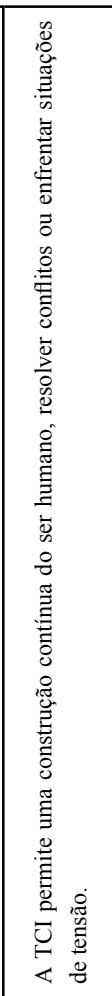 & 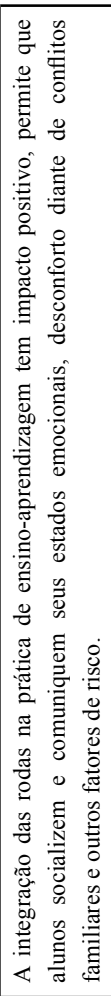 & 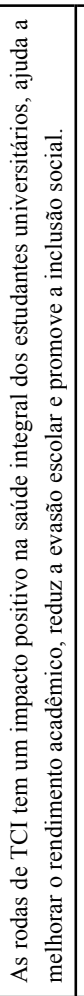 & 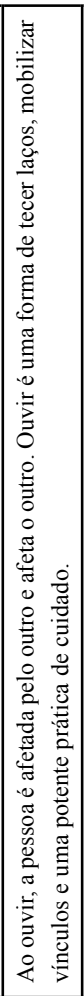 & 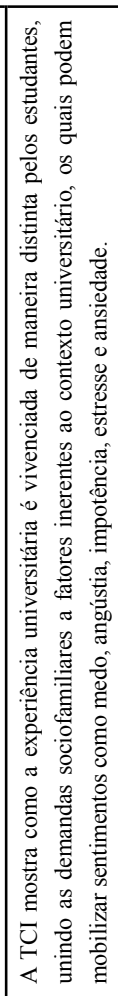 & 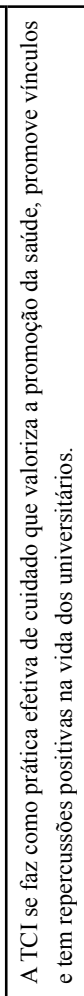 & 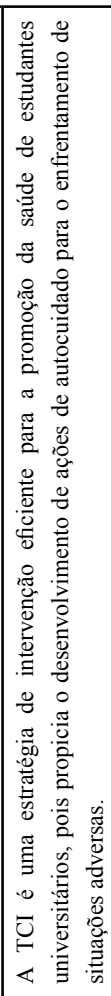 & 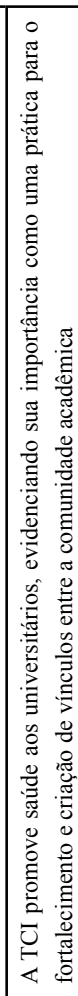 \\
\hline 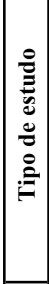 & 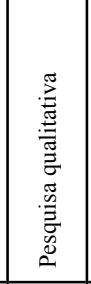 & 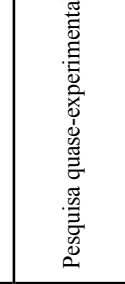 & 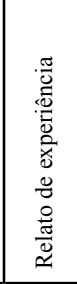 & 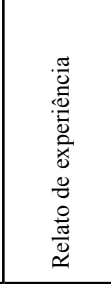 & 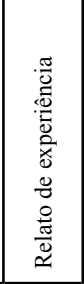 & 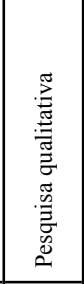 & 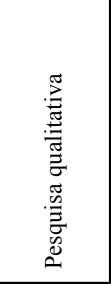 & 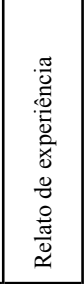 & 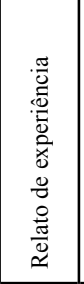 & 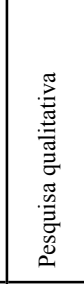 & 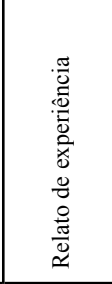 & 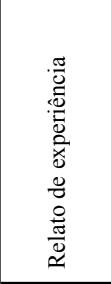 & 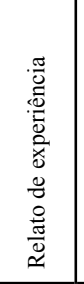 & 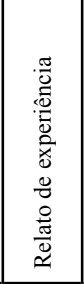 & 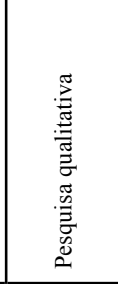 & 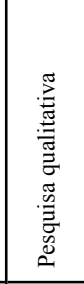 & 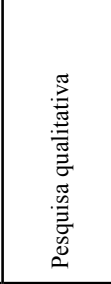 & \\
\hline 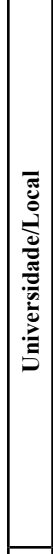 & 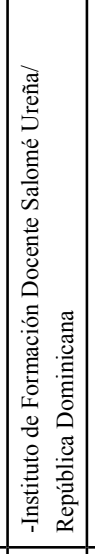 & 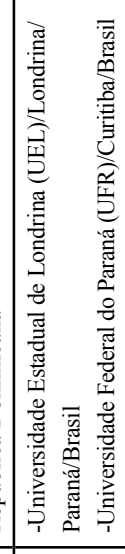 & 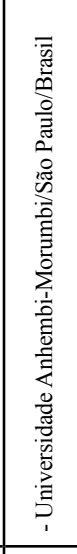 & 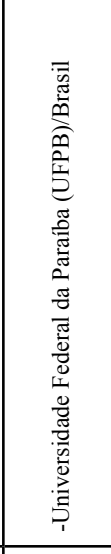 & 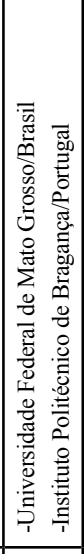 & 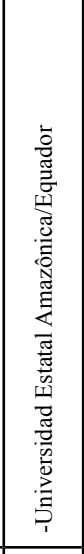 & 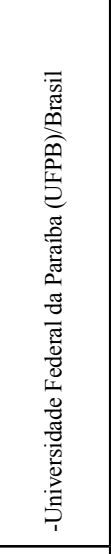 & 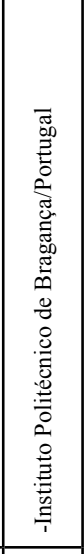 & 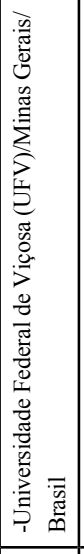 & 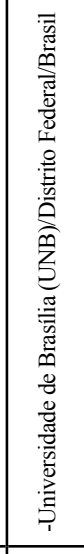 & 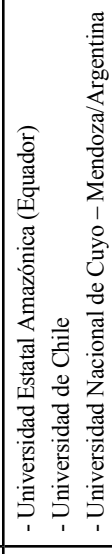 & 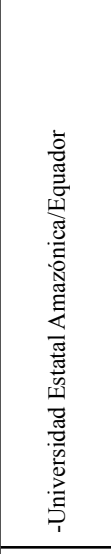 & 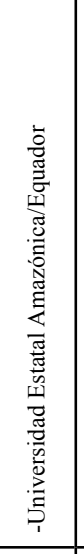 & 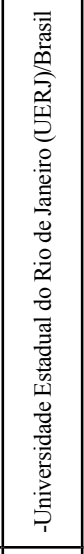 & 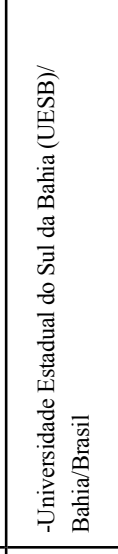 & 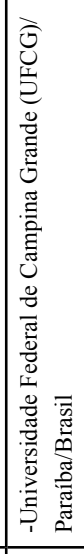 & 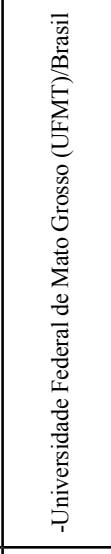 & 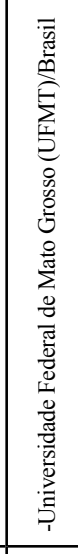 \\
\hline 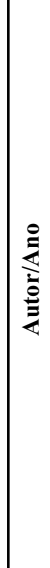 & 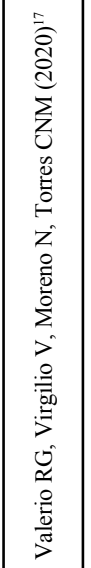 & 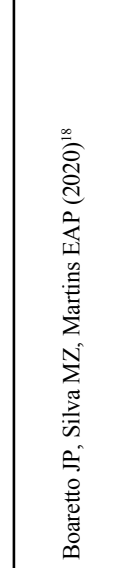 & 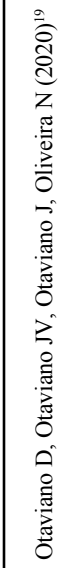 & 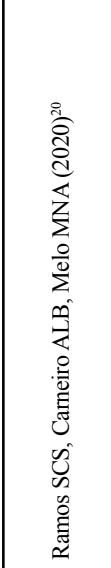 & 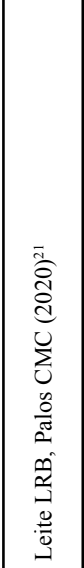 & 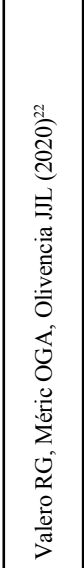 & 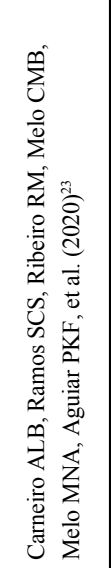 & 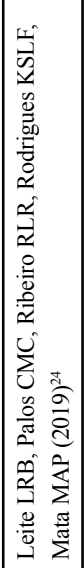 & 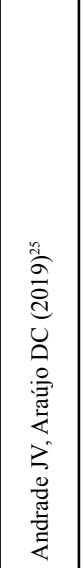 & 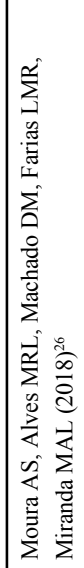 & 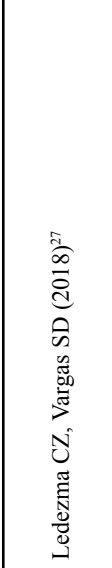 & 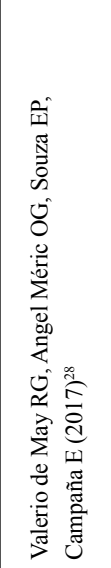 & 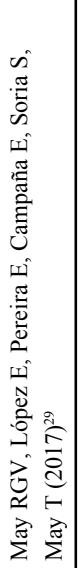 & 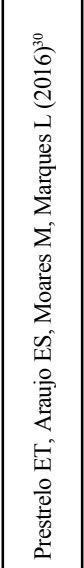 & 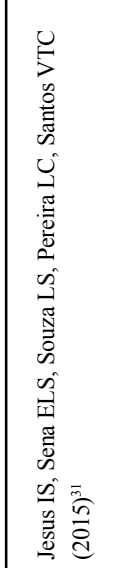 & 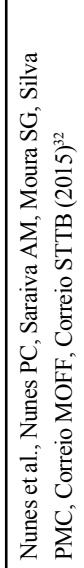 & 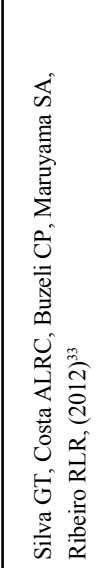 & $\vec{m}$ \\
\hline
\end{tabular}




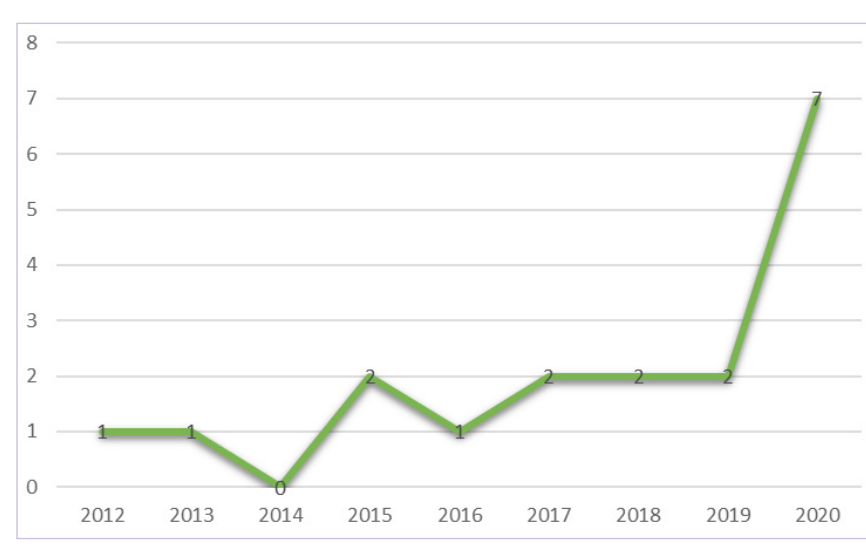

Figura 2. Número de publicações nos últimos 10 anos Fonte: Elaborado pelo autor a partir da revisão de literatura.

A maioria das publicações ocorreu no Brasil (55,6\%): 4 foram da região nordeste $(22,2 \%)$ e 6 das regiões sudeste e centro-oeste brasileiro $(33,4 \%)$, sendo 3 publicações de cada região. Ressalta-se que $38,9 \%$ das publicações vieram de implantações da TCI no exterior, em especial da Argentina, Equador, Chile, República Dominicana e Portugal. Um dos artigos relata a experiência tanto do Brasil quanto de Portugal.
Com a finalidade de sistematizar as informações dos artigos selecionados, os dados foram compilados de maneira descritiva num quadro previamente elaborado pelo pesquisador, o qual contemplou os seguintes tópicos: autores responsáveis; ano de publicação; universidade/local que foi implantada a TCI; tipo de estudo; principais achados nas conclusões. Ressalta-se que essa organização facilitou a identificação e adequação das categorizações temáticas da discussão, no Quadro 1.

Foram evidentes os benefícios tanto pessoais, quando profissionais e comunitários trazidos pela Terapia Comunitária Integrativa no âmbito universitário. Os artigos dessa revisão integrativa apontaram os seguintes benefícios, conforme sistematizado no Quadro 2.

A implantação da TCI foi uma estratégia apropriada para o estudante universitário exercitar a escuta e a fala ${ }^{17,20,21,23,24}$. Além disso, as rodas de terapia comunitária foram vistas como espaço de alívio de sofrimento e compartilhamento de suas angústias sem preconceito ou julgamentos ${ }^{28-30,33-34}$.

De acordo com as premissas da TCI, quando os sentimentos não são expressos e compartilhados com alguém, mais cedo ou mais tarde, podem afetar o bem-estar físico e mental.

Quadro 2. Principais benefícios da TCI no âmbito universitário

\begin{tabular}{|c|c|}
\hline Principais benefícios da TCI no âmbito universitário & Artigos \\
\hline Criação de novas amizades e fortalecimento de amizades já construídas & $22,30,34$ \\
\hline $\begin{array}{l}\text { Desenvolvimento comunitário, sentimento de pertencimento, maior responsabilidade social e } \\
\text { fortalecimento da cidadania }\end{array}$ & $27,28,32,33$ \\
\hline Diminuição da evasão do curso & 17 \\
\hline Ferramenta barata e de fácil acesso de promoção da saúde mental & 23,27 \\
\hline Formação de indivíduos mais críticos e reflexivos & 30 \\
\hline Fortalecimento da resiliência e do enfrentamento da vida & $22,23,24,25,28,32$ \\
\hline Melhora do rendimento acadêmico & 17 \\
\hline Melhora na relação familiar & 28 \\
\hline Organização do pensar e ampliação das alternativas de resolução de problemas pessoais e coletivos & $20,26,28,30,34$ \\
\hline Promoção da saúde mental, manejo das emoções e alívio da carga emocional & $18,20,21,23,25,26,28,29,30,34$ \\
\hline Promoção da saúde e da qualidade de vida & $18,20,23,24,26,31,32,33,34$ \\
\hline Reconstrução e ressignificação de histórias pessoais e coletivas & 34 \\
\hline Reorganização da vida e mudança de comportamento & $20,22,26$ \\
\hline Ressignificação do próprio problema e da própria história da vida & 25,30 \\
\hline Restauração da confiança e da autoestima & $17,22,26,27,28,29,30,32,33,34$ \\
\hline
\end{tabular}

Fonte: Elaborado pelo autor a partir da revisão de literatura. 
Isso corrobora o ditado popular muito usado nas rodas de terapia que diz que "quando a boca cala, os órgãos falam, mas quando a boca fala, os órgãos saram"s.

Dessa maneira, os relatos afirmam que, durantes as rodas de terapia nas universidades, muitos estudantes chegavam com a feição entristecida, preocupada, angustiada ou chorosa; logo na escolha do tema que seria discutido, eram as primeiras pessoas que compartilhavam suas aflições. Isso demonstrou claramente a necessidade de partilhar seus sofrimentos e buscar apoio nas rodas de terapia comunitária ${ }^{33}$.

De acordo com os artigos selecionados, diferentes temas eram trazidos pelos estudantes durante as rodas de terapia. Esses sentimentos e emoções foram sintetizados, conforme Quadro 3.

Além de fala, observou-se que a TCI é um espaço de escuta. Cada pessoa que participa da roda de terapia possui uma visão de mundo. Por isso, qualquer pessoa que participa da roda pode se beneficiar com as outras percepções

Quadro 3. Principais temas e emoções abordados pelos estudantes durante as rodas de Terapia Comunitária no âmbito universitário

\begin{tabular}{|l|l|}
\hline Temas e emoções & Artigos \\
\hline Tristeza, Angústia, Ansiedade e Depressão & $\begin{array}{l}17,18,19,20, \\
21,23,26,32\end{array}$ \\
\hline Conflitos familiares & $\begin{array}{l}17,24,29,31, \\
32,33,34\end{array}$ \\
\hline $\begin{array}{l}\text { Dependência emocional; dificuldade em } \\
\text { expressar sentimentos }\end{array}$ & 23,24 \\
\hline $\begin{array}{l}\text { Dificuldades de relacionamento afetivo/ } \\
\text { amoroso }\end{array}$ & $20,23,24,29,32$ \\
\hline Dificuldades financeiras & $20,29,34$ \\
\hline Discriminação & 17 \\
\hline Estresse com as demandas da faculdade & $17,19,24,29$, \\
\hline Frustração com a vida universitária; & $31,32,33,34$ \\
\hline conflitos com colegas e professores & $17,19,24,26$, \\
\hline Insatisfação com a imagem corporal & 23,34 \\
\hline Luto por causa da perda de entes queridos & $23,33,34$ \\
\hline $\begin{array}{l}\text { Falta de identificação com o curso e medo } \\
\text { da escolha profissional }\end{array}$ & $23,26,31$ \\
\hline Medo do futuro e do futuro profissional & $19,20,21,23,24$, \\
\hline Problemas com álcool e drogas & 24,29 \\
\hline Problemas de saúde em geral & $32,32,34$ \\
\hline Saudade da família e dos amigos & $24,32,33,34$ \\
\hline Sobrecarga de trabalho & 20,32 \\
\hline Solidão & $19,23,27,33,34$ \\
\hline Timidez & 29 \\
\hline Violência doméstica & 17,24 \\
\hline
\end{tabular}

Fonte: Elaborado pelo autor a partir da revisão de literatura. e estratégias que todos encontraram para superar problemas semelhantes ${ }^{20,26,28,30,34}$.

Nesse momento de partilha, o estar próximo e ouvir histórias de pessoas que passam ou já passaram por problemas similares que, por vezes, foram percebidas pelos alunos como novas perspectivas para os impasses, ampliando não só o repertório de ações, mas a possibilidade de voltar a acreditar nas diferentes possibilidades de superar angústias e criar as próprias soluções ${ }^{20,26,30,34}$.

$\mathrm{O}$ fato de outras pessoas exporem estratégias de enfrentamento utilizadas para a resolução de problemas contribuiu para a ressignificação das dificuldades daquele estudante que expôs seu problema na roda terapêutica. Além disso, o estudante teve a opção de acolher essas estratégias e reunir forças para enfrentar suas próprias angústias e aflições ${ }^{25,30}$.

A partir da escuta qualificada exercida durante as rodas de terapia comunitária, diferentes possibilidades de enfrentamento podem surgir, tais como: observar as coisas ao redor, tentar dar um passo de cada vez, estabelecer laços de cumplicidade, buscar psicoterapias, mudar ações e pensamentos, trabalhar a espiritualidade, pensar positivamente frente aos obstáculos da vida, não dar atenção àquilo que não ajuda, não se cobrar tanto, ficar próximo de pessoas que ama, ouvir as pessoas mais velhas e experientes, tornar-se resiliente e recomeçar, dentre outras $22,23,24,25,28,32$.

Assim, quando o estudante tem a possibilidade de participar de rodas de terapia comunitária no próprio ambiente universitário, observou-se que ocorre uma partilha de forma igualitária e circular; cada estudante se tornou terapeuta de si mesmo, a partir das histórias de vida que foram relatadas nas rodas. Nas rodas de TCI, cada um teve a oportunidade de ajudar, ensinar e aprender. Isso gerou um sentimento de igualdade, pertencimento, solidariedade e compaixão com a história da vida do outro ${ }^{26-34}$.

Nesse sentido, observou-se que a TCI é uma importante rede de apoio social que pode ser implantado dentro das universidades. Nesses espaços de inclusão, ocorre um suporte emocional contínuo, acolhimento, confiança e a solidariedade entre todos os participantes. Essa criação de vínculos e laços emocionais auxilia os estudantes a se fortalecerem e enfrentarem os desafios da vida universitária ${ }^{17,21,24,27,28,30,33}$.

A implantação/implementação de rodas de terapia comunitária nas universidades efetivamente podem ser um meio de manejo de situações estressantes, facilitar os espaços de acolhimento e socialização, além de criar conexões e aumentar o vínculo das redes solidárias no contexto universitário. Além disso, as rodas possuem um grande potencial de melhorar o rendimento acadêmico e reduzir o abandono/ evasão dos estudos ${ }^{23,27}$.

Portanto, a TCI ajuda os universitários a descobrir a força que existe dentro deles e suscitar sentimentos e percepções que refletem um aumento da autoestima, o prazer de conviver com outros e buscar novos olhares frente aos seus problemas $^{25,26,30,34}$. 


\section{CONSIDERAÇÕES FINAIS}

Observou-se que TCI tem sido uma importante ferramenta na promoção da saúde mental dos universitários. Ficou claro que a as rodas de terapia, mediadas pela escuta qualificada, propiciou ao estudante a partilha de emoções e sentimentos, a criação de vínculos, a restauração da autoestima, a construção do autocuidado, a ressignificação dos seus problemas e, consequentemente, a busca de novas soluções.

Além disso, evidenciou-se que as estratégias de implantação dessa Terapia no âmbito universitário ocorreram de maneiras distintas: desde ações particulares de professores a projetos de extensão fomentados pela própria instituição de ensino superior. Desta maneira, espera-se que esta revisão possa promover discussões importantes sobre a implantação de programas perenes de promoção da saúde mental no âmbito universitário e incluir as rodas de TCI como espaços de escuta e acolhimento desses estudantes universitários.

\section{REFERÊNCIAS}

1. Gonçalves AM, Sequeira C, Duarte JC, Freitas PP. Ideação suicida em estudantes de ensino superior politécnico: influência de algumas variáveis sociodemográficas, acadêmicas e comportamentais. Millennium 2014; 48(30): 191-203.

2. Papalia DE, Olds SW. Desenvolvimento Humano. Porto Alegre: AMGH; 2013.

3. Padovani RDC, Neufeld CB, Maltoni J, Barbosa LNF, Souza WF, Cavalcanti HAF, Lameu JN. Vulnerabilidade e bem-estar psicológicos do estudante universitário. Revista Brasileira de Terapias Cognitivas 2014; 10(1): 2-10.

4. Pereira FLR, Medeiros SP, Salgado RGF, Castro JNA, Oliveira AMN. Manifestações de ansiedade vivenciadas por estudantes de enfermagem. J. Res: Fundam. care 2019; 11(4): 880-6.

5. Santos RM. Perfil de ansiedade em estudantes universitários de cursos da área da saúde. Campina Grande; 2014. [Mestrado Dissertação - Universidade Estadual da Paraíba]. [acesso em 3 mar 2021]. Disponível em: http://tede.bc.uepb.edu.br/jspui/ bitstream/tede/2269/2/PDF\%20-\%20R\%C3\%B4mulo\%20 Moreira\%20dos\%20Santos.pdf

6. Vasconcelos TC, Dias BRT, Andrade LR, Melo GF, Barbosa L, Souza E. Prevalência de Sintomas de Ansiedade e Depressão em Estudantes de Medicina. Rev. Bras. Educ. Med. 2014; 39(1): 135-142.

7. Fernandes MA, Vieira FER, Avelino FVSD, Santos JDM. Prevalência de sintomas ansiosos e depressivos em universitários de uma instituição pública. Rev. Bras. Enferm. 2018; 71(Supl. 5): 2169-2175.

8. Barreto AP. Terapia Comunitária: passo a passo. Fortaleza: Gráfica LCR; 2019.
9. Carvalho MAP, Romero ROG, Ferreira Filha MO. Terapia comunitária no centro de apoio psicossocial: concepções dos acadêmicos de enfermagem. Rev. Enferm. UFPE on line 2013; 7(6): 4389-94.

10. Ministério da Saúde (BR). Portaria $\mathrm{n}^{\circ} 849$, de 27 de março de 2017. Inclui a Arteterapia, Ayurveda, Biodança, Dança Circular, Meditação, Musicoterapia, Naturopatia, Osteopatia, Quiropraxia, Reflexoterapia, Reiki, Shantala, Terapia Comunitária Integrativa e Yoga à Política Nacional de Práticas Integrativas e Complementares. Diário Oficial União, 28 Mar 2017. Seção 1:68. [acesso em 3 mar 2021].

Disponível em: https://bvsms.saude.gov.br/bvs/saudelegis/ gm/2017/prt0849_28_03_2017.html

11. Cezário PFO, Araújo LL, Pereira TLB, Teixeira OFB, Abrandes AWB, et al. Integrative Community Therapy and its Benefits for Primary Care: an integrative review. Int Arch Med 2015; 8(267): 1-9.

12. Freire P. Paulo Freire ao Vivo. São Paulo: Loyola; 1983.

13. Braga LAV, Dias MD, Ferreira Filha MO, Moraes MN, Arauna MHM, Rocha IA. Terapia comunitária e resiliência: história de mulheres. Rev. Pesqui. (Univ Fed Estado Rio J) 2013;5(1).

14. Reis MLA. Quando me encontrei voei: o significado da capacitação em Terapia Comunitária Integrativa. Porto Alegre: CAIFCOM Editora; 2017.

15. Ferreira Filha MO, Dias MD, Andrade FB, Lima EAR, Ribeiro FF, Silva MSS. A terapia comunitária como estratégia de promoção à saúde mental: o caminho para o empoderamento. Rev. Eletr. Enf. 2009; 11(4): 964-970.

16. Coriolano-Marinus MWL, Queiroga BAM, Ruiz-Moreno L, Lima LS. Comunicação nas práticas em saúde: revisão integrativa da literatura. Saúde Soc. 2014; 23(4): 1356-69.

17. Valerio RG, Virgilio V, Moreno N, Torres CM. Herramientas pedagógicas innovadoras em el Recinto "Uránias Montás", San Juan de la Maguana, República Dominicana. International Journal of New Education 2020; 3(1): 99-115.

18. Boaretto JP, Silva MZ, Martins EAP. Ansiedade e depressão na universidade: contribuições da terapia comunitária integrativa. Temas em Educ. e Saúde 2020; 16(esp 1): 296-310.

19. Otaviano D, Otaviano JV, Otaviano J, Oliveira N. Terapia Comunitária Integrativa: uma prática mobilizadora de autocuidado e educação emocional e saúde integral para estudantes do curso de Medicina. Temas em Educ. e Saúde 2020; 16(esp 1): 422-31.

20. Ramos SCS, Carneiro ALB, Melo MNA. Conexão Terapia Comunitária Integrativa (TCI) e Saúde Mental. Revista Interdisciplinar em Saúde 2020; 7(1): 1505-15.

21. Leite LRB, Palos CMC. Do centro-oeste brasileiro ao norte português: experiência(s) com a Terapia Comunitária 
Integrativa. Temas em Educ. e Saúde 2020; 16(esp 1): 286-95.

22. Valero RG, Méric OGA, Olivencia JJL. Análise discursiva das apreciações das rodas vinculantes no contexto universitário latino-americano. Temas em Educ. e Saúde 2020; 16(esp 1): 239-55.

23. Carneiro ALB, Ramos SCS, Ribeiro RM, Melo CMB, Melo MNA, Aguiar PKF, et al. Integrative Community Therapy in Times of Pandemic: meetings, enchantments, interactions, experiences and sharing which transcend the screens. Res., Soc. Dev. 2020; 9(11): 1-42.

24. Leite LRB, Palos CMC, Ribeiro RLR, Rodrigues KSLF, Mata MAP. Projeto Laços: promoção de saúde mental com a Terapia Comunitária Integrativa - Relato de Experiência. AdolesCiência

- Revista Júnior de Investigação 2019; 6(1): 96-116.

25. Andrade JV, Araújo DC. O uso da terapia comunitária como estratégia para apoiar estudantes. Vivências 2019; 15(28): 165-70.

26. Moura AS, Alves MRL, Machado DM, Farias LMR, Miranda MAL. O estudante de graduação e a vivência em rodas de Terapia Comunitária. Com. Ciências Saúde 2019; 29(04): 1-10.

27. Ledezma CZ, Vargas SD. La Terapia Comunitaria Integrativa Sistémica: experiencias socio-comunitarias y aprendizajes de su aplicación em Ecuador, Argentina y Chile. Trenzar 2018; (1): 1-17.
28. Valerio de May RG, Angel Méric OG, Souza EP, Campaña E. Impacto das rodas no contexto universitário e comunitário. Temas em Educ. e Saúde 2017; 13(2): 335-47.

29. May RGV, López E, Pereira E, Campaña E, Soria S, May T. Ruedas vinculantes como espacio de inclusión en el contexto universitario: la experiencia de la Universidad Estatal Amazónica, Puyo, Pastaza, Ecuador. Temas em Educ. e Saúde 2016; 12(1): 97-107.

30. Prestrelo ET, Araujo ES, Moares M, Marques L. Ouvir é como a chuva: o apoio psicológico como parte da formação em psicologia. Pesqui. Prát. Psicossociais 2016; 11(1): 86-99.

31. Jesus IS, Sena ELS, Souza LS, Pereira LC, Santos VTC. Vivências de estudantes de graduação em enfermagem com a ansiedade. Rev. Enferm. UFPE on line 2015; 9(1): 149-57.

32. Nunes PC, Saraiva AM, Moura SG, Silva PMC, Correio MOFF, Correio STTB. Coração de estudante: a terapia comunitária integrativa no contexto universitário. J. Res: Fundam. Care on line 2015; 7(3): 2919-29.

33. Silva GT, Costa ALRC, Buzeli CP, Maruyama SA, Ribeiro RLR. Significados da participação em roda de Terapia Comunitária para os estudantes de uma universidade pública. Cienc. Cuid. Saúde 2013; 11(3): 445-53.

34. Buzeli CP, Costa ALRC, Ribeiro RLR. Promoção da Saúde de Estudantes Universitários: contribuições da Terapia Comunitária. Rev. Gestão \& Saúde 2012; 3(1): 332-34.

\section{ABSTRACT}

Objective: To verify the performance of Integrative Community Therapy as a health promotion strategy at the university level. Method: This is an integrative literature review, carried out in December 2020 and had as inclusion criteria articles in English, Spanish or Portuguese, published in the last ten years, available in full, that contemplated the theme proposed for this research and published in the databases of the Virtual Health Library (VHL), the CAPES Journal Portal and Scientific Literature (SCILIT). Results: It was found 398 articles, of which 18 were selected for this study. Brazilian and foreign higher education institutions implanted and implemented the Community Therapy circles as spaces for welcoming, active listening, creating bonds, as well as promoting health and promoting the mental health of their university students. Conclusion: Integrative Community Therapy is a powerful tool for health promotion and in the last five years this practice has been strengthened in universities.

Keywords: Complementary Therapies; Mental health; University; Health promotion

\section{RESUMEN}

Objetivo: Verificar la integración de la Terapia Integrativa Comunitaria como estrategia de promoción de la salud en el ámbito universitario. Método: Se trata de una revisión integradora de la literatura, realizada en diciembre de 2020. Sus criterios de inclusión son artículos en inglés, español o portugués, publicados en los últimos diez años, que se encuentran disponibles en su totalidad, incluyen el tema propuesto para esta investigación y están publicados en las bases de datos de la Biblioteca Virtual en Salud (BVS), el Portal de la Revista CAPES y Literatura Cientifica (SCILIT). Resultados: Se encontraron 398 artículos, de los cuales 18 fueron seleccionados para este estudio. Las Instituciones de Educación Superior brasileñas y extranjeras implantan e implementan Ruedas de Terapia Comunitaria como espacios de acogida, escuelas activas, creando vínculos, además de promover la salud y promover la salud mental de sus estudiantes. Conclusión: Sé que la Terapia Integrativa Comunitaria es una poderosa herramienta para la promoción de la salud y, en los últimos cinco años, esta práctica se ha fortalecido en las universidades.

Palabras clave: Terapias complementarias; Salud mental; Universidad; Promoción de la salud. 